\title{
Tra cứu nhanh về hai chủ đề quan trọng với học giới
}

\author{
Lê Tâm Trí
}

Nguyễn Minh Hoàng

Tp. Hồ Chí Minh, ngày 26 tháng 2 năm 2022

Hai chủ đề nhóm nghiên cứu chúng tôi quan tâm là hiệu quả đâuu tư cho nghiên cứu (bao gồm cả xuất bản) và những vấn đề xung quanh việc rút bài đã đăng (sau peer review). Chúng thuộc mảng nghiên cứu chính sách khoa học tổng quát (science policy) và có liên quan tới cả triết học khoa học (philosophy of science).

Hai từ khóa để tìm kiếm nhanh với Google Scholar là "retractions" và "cost of science"

Hai hình dưới đây là các kết quả phía trên cùng của hai lượt tìm kiếm (không đặt cụm từ trong dấu ngoặc kép).

Với chủ đề Retractions:

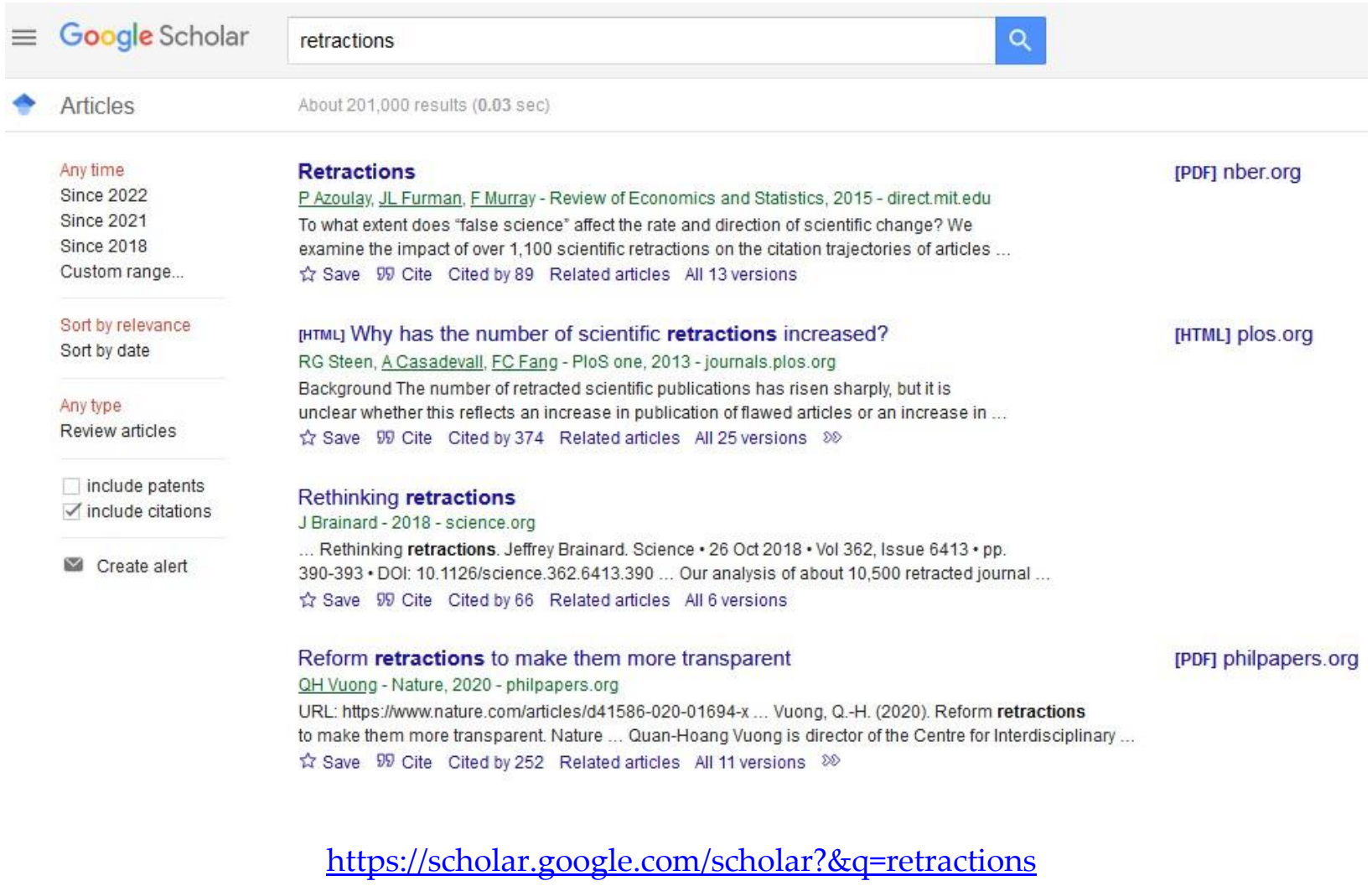


Những bài xuất hiện trên cùng đều khá mới, từ năm 2013 trở lại đây. Nếu rà soát hết cả trang đâu tiên, thì bài cũ nhất cũng mới chỉ từ năm 2006, trên Science (Miller, 2006).

Với chủ đề Cost of science:

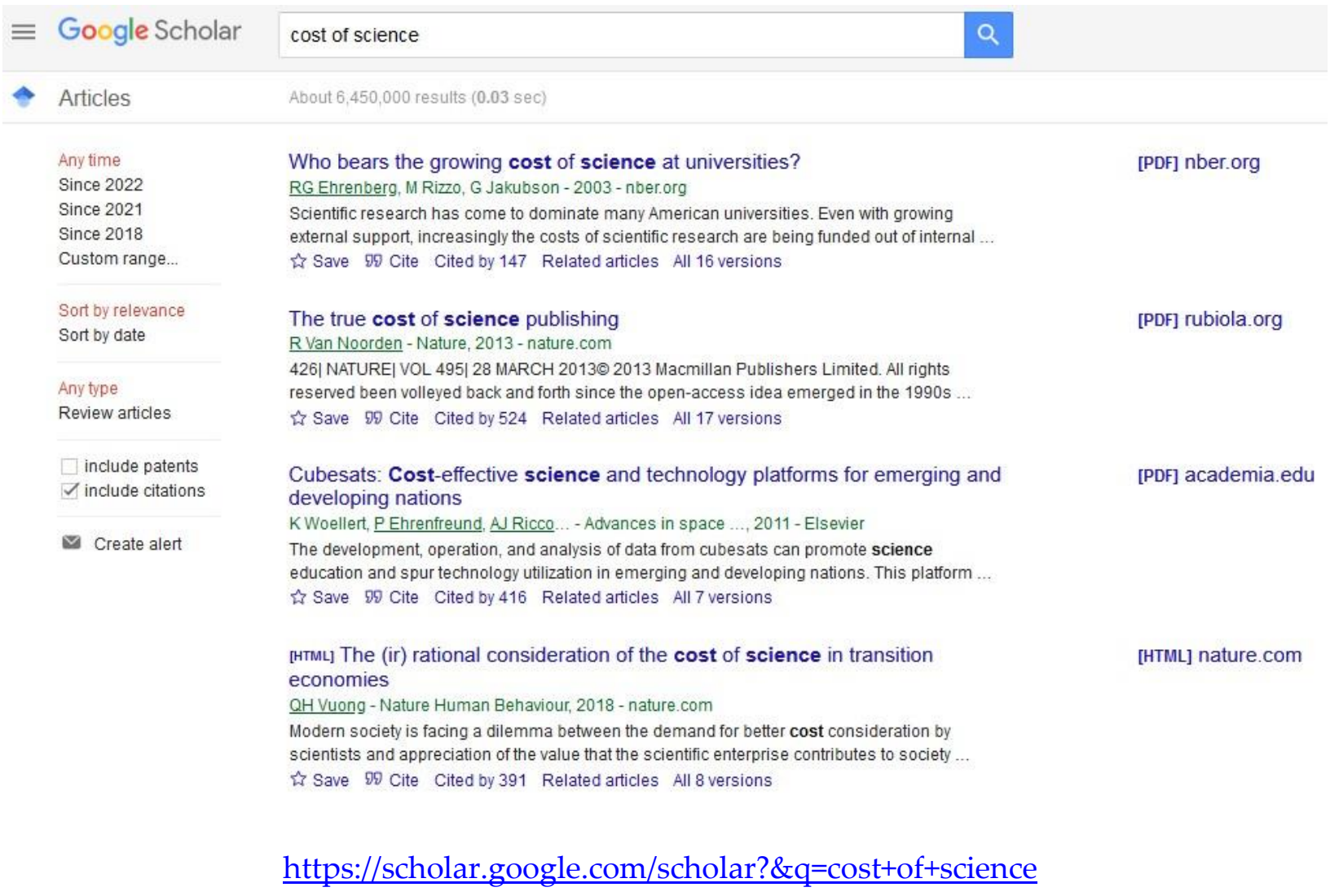

So với từ khóa retractions, thì các kết quả của từ khóa cost of science cho thấy thời gian từ trước. Bài lâu đời nhất là Stecher \& Klein (1997) trên Educational Evaluation and Policy Analysis. Tuy nhiên, về cơ bản thì những kết quả tìm kiếm có vị trí trên cùng cũng vẫn có thể được coi là rất mới, chỉ trong khoảng chục năm trở lại đây.

Đồng thời, một thực tế quan sát thấy nữa cũng rất đáng chú ý. Trong số 10 bài lọc ra xem xét từ 2 tìm kiếm nói trên, thì 5 bài thuộc về họ Science và Nature. Và chắc chắn điều này không phải là tình cờ. Các nhóm vấn đề tổng quát của khoa học nhân loại xưa nay vẫn thuộc đối tượng ưu tiên xuất bản của hai hệ thống ấn phẩm hàng đầu nói trên.

\section{References}

Azoulay, P., Furman, J. L., \& Murray, F. (2015). Retractions. Review of Economics and Statistics, 97(5), 1118-1136. 
Brainard, J. (2018). Rethinking retractions. Science, 362(6413), 390-393.

Ehrenberg, R. G., Rizzo, M., \& Jakubson, G. (2003). Who bears the growing cost of science at universities?. NBER Working Paper 9627. https://www.nber.org/papers/w9627

Miller, G. (2006). A scientist's nightmare: software problem leads to five retractions. Science, 314(5807), 1856-1857.

Steen, R. G., Casadevall, A., \& Fang, F. C. (2013). Why has the number of scientific retractions increased?. PLoS One, 8(7), e68397.

Stecher, B. M., \& Klein, S. P. (1997). The cost of science performance assessments in large-scale testing programs. Educational Evaluation and Policy Analysis, 19(1), 1-14.

Van Noorden, R. (2013). The true cost of science publishing. Nature, 495(7442), 426-429.

Vuong, Q. H. (2018). The (ir)rational consideration of the cost of science in transition economies. Nature Human Behaviour, 2(1), 5.

Vuong, Q. H. (2020). Reform retractions to make them more transparent. Nature, 582(7811), 149.

Woellert, K., Ehrenfreund, P., Ricco, A. J., \& Hertzfeld, H. (2011). Cubesats: Cost-effective science and technology platforms for emerging and developing nations. Advances in Space Research, 47(4), 663-684. 